\title{
A FRAMEWORK METHODOLOGY TO SUPPORT THE SELECTION OF A MULTIPURPOSE FIGHTER
}

\author{
Todor TAGAREV, Gueorgui STANKOV, Lozan BIZOV, and \\ Atanas NATCHEV
}

\begin{abstract}
The procurement of multipurpose fighter planes is one of the major procurement, or modernization projects, announced by Bulgaria's Ministry of Defense in 2002, but a procurement case has not been initiated so far. This article calls for a transparent decision-making process within a rational framework, based on both qualitative and quantitative analysis, that would allow to select "the best" multipurpose fighter for the Bulgarian Air Force. After outlining the main assumptions, the authors examine the issue of identifying and structuring the criteria for selection of a multipurpose fighter, describe the main steps of a rational, quantitatively-based, transparent decision-making process and analyze the major decision support requirements, as well as methods and tools that may be used in providing analytical support to both the selection process and the follow-on contract and project management.
\end{abstract}

Keywords: Defense procurement, defense acquisition management, decision support, DSS, AHP, transparency, contract management, risk management.

\section{Introduction}

Since the beginning of Bulgaria's defense reform in 1999, the Air Force enjoys a position of higher priority in the plans for modernization of the Bulgarian Armed Forces. Considerable part of the defense investments since the 1997 decision of the country to seek membership in NATO dealt with primary interoperability issues, i.e., command and control, strategic and tactical communications, air surveillance and exchange of related information, and host nation support requirements. ${ }^{1}$ Another portion of the investments addressed immediate requirements of the increasing contribution of the Bulgarian Armed Forces to peace operations in the Balkans and, later, in the international operations in Afghanistan and Iraq.

In the first five years of reform only the Air Force received new platforms and started sizeable programs to upgrade legacy equipment. First, the Ministry of Defense pro- 
cured six Bell-206 helicopters (primarily for training) and one Bell-430. ${ }^{2}$ The procurement of Pilatus aircraft followed - the Air Force received six PC-9M aircraft for training and one PC-12 for VIP transport. A contract for the delivery of twelve helicopters AS 532AL "Cougar" for the Air Force (plus six AS 565 MB "Panther" for the Navy), estimated at approximately USD 300 million, was signed in 2004 and three of the "Cougars" have been delivered. In 2005, the MOD signed a contract for procurement of five transport aircraft C-27J Spartan, estimated at 91 million Euro, with an option for three additional airplanes, and the first one of these is expected in August 2007. Contracts were signed for overhaul and upgrades of a squadron of MiG-29 fighters and for Mi-24 and Mi-17 helicopters. ${ }^{3}$ In addition, the Ministry of Defense invested in upgrading airfields, as well as in the performance and the interoperability of the air defense system (which in Bulgaria is part of the Air Force) through modernization of air surveillance radars, IFF, and building of a new Air Sovereignty Operations Center.

Nevertheless, all these investments pale in comparison to the expected procurement of a squadron of multipurpose fighter planes. ${ }^{4}$ This procurement is of considerable importance not only because of the cost involved; it relates to the prestige of the military, and the Air Force in particular, potentially provides for an air defense role of Bulgaria in parts of South East Europe, and enjoys heightened societal interest. Moreover, any procurement decision will be accompanied by a very intensive struggle among the services for a share of the limited defense investment budget.

Therefore, the high cost involved and the interest towards the potential procurement of multipurpose fighters for the Bulgarian Air Force among political and military elites, experts in and outside the Government, businesses and society, as well as international businesses and lobbies, calls for a fairly transparent decision-making process within a rational, commonly understood and agreed decision-making framework. This paper presents a possible outline for such decision-making framework and overview of the support that the operational analysis community may provide to the selection, as well as to contract and project management decisions.

\section{Key Assumptions}

Any transparent decision-making process requires clear identification and, often, deliberation on key assumptions. In the national experience, assumptions are rarely stated publicly and, thus, cannot be challenged. Our analysis outlines four key assumptions for this particular procurement.

First, Bulgaria will not set its own requirements for development of a future aircraft (and certainly will not develop its own aircraft). The country will select among available fighters. Furthermore, and given predicted costs of fighters under development, 
the country will select among fighters that are currently available on the market. ${ }^{5}$ Possibly, the Ministry of Defense will set some unique, but minor requirements towards the platforms and/or maintenance equipment. One example would be the provision of full documentation package in the Bulgarian language. However, such requirements are not expected to be among the important considerations in the selection process.

Secondly, most probably Bulgaria will conduct its own tender, without cooperating with other countries planning to procure multipurpose fighters in the near future. The combination of procurement projects of two or more countries is still a possibility, although fairly distant one at this stage. Nevertheless, compatibility of analysis and approaches to selection and project management is an important consideration in order to assure common understanding of requirements and proposals, as well as to provide opportunities for future cooperation with other countries in operating and maintaining the same type of aircraft and, thus, to lower operations and maintenance costs.

Thirdly, the sheer cost of this project raises strong expectations that this and other similar defense procurements will be used to generate investments in the country and to create other economic benefits through the mechanism of offsets. Recently, Bulgaria's Prime Minister Mr. Sergey Stanishev welcomed the changes in the offset regulations ${ }^{6}$ and presented the offset programs as a tool "to bring additional investments in the Bulgarian economy, that will lead to higher levels of economic growth, technology transfer and creation of new jobs." 7

The formulation of the fourth and last among the key assumptions is based on analysis of the experience and reasonable forecasts of the defense budget. The procurement of multipurpose fighters may be signed only using a loan that is guaranteed by the Bulgarian state. The practice is that the prospective supplier joins forces with a powerful financial institution that is willing to provide the loan. Then, this loan will be paid off from the defense budget over a number of years.

\section{Criteria for Selection}

There are dozens, possibly hundreds indicators by which we can judge whether and to what extent a particular aircraft suits the needs of the Bulgarian Air Force, or rather Bulgaria's security and defense policy. A subset of the respective requirements should be set as criteria in advance to the initiation of the selection procedure. For convenience, this paper presents the possible criteria clustered in three main groups, related to performance, cost, and economic impact. Additional criteria are included in one of these three groups even though strictly speaking they may not perfectly fit the chosen name for the group. 


\section{Performance Criteria}

Aircraft speed, altitude, range, agility, weapon load and stand-off capabilities, sensors and electronic suites, protection, day/night and weather-related capabilities, take-off and landing requirements, etc., are key considerations in the selection of an aircraft. ${ }^{8}$ The respective criteria should be clearly related to foreseen missions and, respectively, set primarily in operational terms.

System requirements may also be included in this group of criteria, especially when they are related to interoperability and compatibility with existing infrastructure. Particular technical specifications cannot be set as "criteria," unless they are solidly justified, e.g. if the aircraft needs to fit in existing hardened shelters. ${ }^{9}$

One particular sub-group of criteria is based on necessary, and expected, availability and the respective reliability and maintainability requirements. These relate, in part, to the system of maintenance for the aircraft, which as discussed bellow, impacts aircraft life cycle costs.

\section{Cost}

Much too often decision makers focus their attention on the upfront cost, i.e. the cost to procure the aircraft per se. Of primary importance in the formulation of cost criteria, however, is to account for "full cost" both in terms of package, necessary to operate and maintain the aircraft, and costs throughout its life cycle.

Since Bulgaria's defense establishment has very limited experience with the notion of "full cost," and in order to provide "interoperability" in the communication with potential contractors and possible future partners in procurement and/or maintenance of the aircraft, it is strongly recommended to use commonly accepted cost breakdown structures and life cycle cost models. ${ }^{10}$

Given the forth among the key assumption above, in the formulation of cost-related criteria Bulgarian defense officials need to account for the full cost to refund the loan, i.e. interest rates, etc., but also for perceptions on what is a good balance between immediate and future financial obligations to be covered by the defense budget.

\section{Economic Impact}

Since January 2007 Bulgaria requires offset obligations for at least 110 percent of the contract cost. The new Regulations for Granting Special Public Contracts in effect predefine the selection criteria, related to the economic impact of the procurement of multipurpose fighters. The Regulations further fix the ration between direct and indirect offsets and authorize the Ministry of Economy and Energy to deal with the offset aspects of the procurement. Thus, only the volume of the offset obligations may be 
seen as a criterion among all others for selection of a supplier; the Ministry of Economy and Energy deals with all indirect offset arrangement, and the Ministry of Defense - with the direct offsets.

Implicitly or explicitly, the Ministry of Defense may include requirements towards bidders that would guarantee a degree of independence of the country in maintaining and operating the aircraft. Some of these may take the form of offset requirements.

In this group or separately, decision makers may decide to account for a number of additional factors, such as expected negative environmental impact of the new weapon system, the necessity to build a new base, to expand or to close down an existing one, and the respective communal impact, etc.

One special group of criteria may relate to the arrangement for management of the procurement contract and the whole project, such as:

- Rate and time of delivery

- Risk management conditions, etc.

\section{Decision-making Process}

Decision making is a process of choosing among alternative courses of action for the purpose of attaining a goal or goals. ${ }^{11}$ Turban and co-authors identify four distinct phases of the decision-making process: (1) intelligence, (2) design, (3) choice, and (4) implementation. ${ }^{12}$

In regard to acquisition decision making and focusing on the selection of a supplier, Elisabeth Wright further subdivides eight phases in the development of acquisition strategy: ${ }^{13}$

1. Identification and commitment of the right resources

2. Collection of background information and data

3. Synthesis of information

4. Identification of optional strategies

5. Further development of best optional strategies

6. Identification and integration of "best choice" strategies

7. Evaluation of best choices

8. Final risk assessment and risk mitigation.

The intelligence phase covers identification and definition of the problem at hand; setting organizational objectives; data collection (with account of data collection costs, accuracy, objectivity, and potential information overload); problem classification and statement; problem decomposition. ${ }^{14}$ Communication among decision mak- 
ers and decisions on process ownership are important, albeit often neglected requirements towards this phase.

In the design phase, functional area specialists and analysts together define variables, relationships, criteria, and create adequate models. Then they propose principles of choice, identify alternative courses of action, consider how to deal with risk, develop/generate alternatives, identify alternative solutions, predict and measure potential outcomes.

The choice involves solving the model and conducting sensitivity analysis. The phase culminates in selection of "best" or good alternative or alternatives.

During the implementation phase a number of feedback loops are used to refine models in order to better manage risk during the implementation of the contract and the whole project.

Although usually a Minister or a designated Deputy Minister makes the final decision, group decision making is prevalent in the process.

\section{Analysts in Decision Support Roles}

The operational analysis community is able to provide decision support in almost all phases and aspects of the decision making process. This section of the essay gives a glimpse on important decision support requirements and possible analytical roles, methods and tools.

First and foremost, analysts are able to assist defense officials in bounding and structuring the problem of selecting a multipurpose fighter.

Secondly, rigorous analysis is indispensable in translating poorly structured concepts and requirements of security and defense policy into performance requirements for the fighter. ${ }^{15}$ The creation of a typical goal structure (selection criteria) should account for fighter missions and tasks to be performed over a set of diverse scenarios, fighter capabilities and characteristics, and to provide a suitable metrics while working with different timeframes.

Key is the role of analysts in dealing with multiple criteria with hierarchical structure and complex relationships in order to compare a number of alternatives. Typical tasks involve normalization of criteria, assigning quantitative measures for qualitative attributes, usually through the use of utility functions, checking for consistency, processing expert estimates, etc.

In addition, typically analysts are involved in devising cost structure models and, in particular, life cycle cost models, as well as analyzing statistics compiled over the years and related to diverse platforms. 
Another key analysis task based on assessment of potential performance and costs is to rank alternatives according to cost-benefit criteria. ${ }^{16}$ Recently, Bulgaria's Ministry of Finance introduced rigorous requirements towards the management of all public investment projects, including requirements for provision of convincing cost-benefit assessment prior to the allocation of requested finances. ${ }^{17}$

For projects of this magnitude, scientists are often tasked to develop and/or adapt decision support systems (DSS) in order to facilitate the work of the selection team, save time, alleviate mistakes, visualize alternatives and results, etc. From mathematical standpoint decision support involves the use, and DSS typically implement techniques for multi-criteria decision-making such as Analytical Hierarchic Process (AHP), Multi-attribute utility theory, Concordance analysis, Regime Method, Evamix Method, ELECTRE, Weighted summation, Ideal point method, etc. ${ }^{18}$ Examples of implementations of DSS systems are Expert Choice, Force Matrix Model, ${ }^{19}$ etc.

Further to the selection of the "best" aircraft, analysts may support the Integrated Project Management Team in planning and overall project management. In addition

to general purpose project management methodologies, such as PERT/CPM, ${ }^{20}$ the key challenge here is to manage requirements throughout the selection, contracting and the delivery processes. DOORS is an example of a requirements management DSS that is adequate to such complex projects. ${ }^{21}$

In conclusion, the selection of a multipurpose fighter for Bulgaria's Air Force is a complex, semi-structured problem, which involves very high expectations and costs. Recently, the regulatory framework in the country placed much higher requirements for transparency in decision making and cost-efficiency of public investments, including defense investments. We reason in this essay that to meet these requirements is far from trivial. On the contrary, it demands elaborated decision-making frameworks and use of solid analytical capacity. The essay provides a sketch for the decision framework and the respective methodology and informs decision makers on decision support requirements and key roles of the analytical community in the process of fighter selection.

\section{Acknowledgement}

This paper reflects research on project SfP 981149 "Operations Research Support to Force and Operations Planning in the New Security Environment," sponsored by NATO's Scientific Affairs Division in the framework of the Science for Peace Program. 


\section{Notes:}

1 Volume 6 of Information \& Security, <http://www.isn.ethz.ch/pubs/ph/details.cfm?lng=en\& id=773>, addressed the priorities of modernization. See for example the article Todor Tagarev, "Prerequisites and Approaches to Force Modernization in a Transition Period," Information \& Security: An International Journal 6 (2001): 30-52.

2 See <www.airforce-bg.com/helicopters.html> (27 May 2007).

${ }^{3}$ Most of these, however, failed.

${ }^{4}$ See Armed Forces Modernization Plan 2002 - 2015 (Sofia: Ministry of Defense, 2004), <http://www.mod.bg/en/modern.html\#>; and Summary of the Basic Projects for Modernization of the Bulgarian Armed Forces (Sofia: Ministry of Defense, September 2004). Project \# 3 in the list of the 11 main modernization projects is "Acquisition of a new Multi-role Fighter."

5 Which means that by the time it is fully operational, the Bulgarian fighter force will be ten to thirty years behind its more technologically advanced allies and possible "peer competitors."

${ }^{6}$ With its Ordnance \# 1 for 2007, the Council of Ministers enforced new Regulations for Granting Special Public Contracts, published in State Gazette 7 (January 2007). For any defense contract amounting to over 10 million BGN, a foreign contractor is obliged to sign offset deals for no less than 110 percent of the cost of the defense procurement, and 70 percent of these shall be "indirect offsets."

7 Sergey Stanishev, Prime Minister of the Republic of Bulgaria, Speech to the International Conference "Offset in Bulgaria: Current Challenges and Perspectives" (Sofia, 19-20 February 2007), unofficial translation by the authors. The speech is available in Bulgarian at <www.natoinfo.bg/SpeechesAndDiscussions/Stanishev_offset.htm> (12 April 2007).

${ }^{8}$ For a structured and detailed presentation of performance requirements see the article by Venelin Georgiev, "Analysis of Alternatives: An Efficient Tool in Managing Force Modernization Projects" in this volume of Information \& Security.

9 Such requirement may not be included among the selection criteria, but then the cost for building such shelters (if still necessary) should be included among the costs of the respective alternative.

${ }^{10}$ A number of NATO RTO studies provide a good starting point. See Cost Structure and Life Cycle Costs for Military Systems, RTO Technical Report TR-058 (Paris: RTA, September 2003), <www.rto.nato.int/panel.asp?panel=SAS\&topic=pubs\#>, and Marcel Smit, Arthur Griffiths, et al., Methods and Models for Life Cycle Costing, Pre-released RTO Technical Report (Paris; RTA, January 2007).

${ }^{11}$ Efraim Turban, Jay A. Aronson, and Ting-Peng Liang, Decision Support Systems and Intelligent Systems, $7^{\text {th }}$ ed. (Upper Saddle River, NJ: Pearson Prentice Hall, 2005), 40.

${ }^{12}$ Turban, Aronson, and Liang, Decision Support Systems and Intelligent Systems.

${ }^{13}$ Elisabeth Wright, "Twenty First Century Defense Acquisition: Challenges and Opportunities," Connections: The Quarterly Journal 5, no. 1 (Spring-Summer 2006): 71$80,<$ https://consortium.pims.org/twenty-first-century-defence-acquisition-challenges-andopportunities>.

${ }^{14}$ Recognizing that even poorly structured problems may have highly structured sub-problems. This study may serve as an example. 
${ }^{15}$ See as an example the article by Velizar Shalamanov, "2020 Air Force Mission Capabilities Packages from Operational Analysis Perspective" in this volume.

${ }^{16}$ On cost-benefit analysis with emphasis on public spending see, for example, Anthony E. Boardman, David H. Greenberg, Aidan R. Vining, and David L. Weimer, Cost Benefit Analysis: Concepts and Practice, $3^{\text {rd }}$ ed. (Upper Saddle River, NJ: Pearson Prentice Hall, 2006); Diana Fuguitt and Shanton J. Wilcox, Cost-Benefit Analysis for Public Sector Decision Makers (Westport, Connecticut: Quorum Books, 1999).

${ }^{17}$ Guidance on Analyzing Investment Projects According to Cost and Benefits (Sofia: Ministry of Finance, 2006).

${ }^{18}$ See, for example, Frederick S. Hillier and Gerald J. Lieberman, Introduction of Operations Research, $8^{\text {th }}$ ed. (Boston, MA: McGraw Hill, 2005); and Turban, Aronson, and Liang, Decision Support Systems and Intelligent Systems.

${ }^{19}$ Developed by Lockheed Martin Aeronautics Company. An article by Robert K. Murphy and G. Richard Cathers in the forthcoming volume of Information \& Security will present this model.

${ }^{20}$ Hillier and Lieberman, Introduction of Operations Research, CD-ROM Supplement, Chapter 22.

${ }^{21}$ Telelogic's DOORS $\AA$ is designed to facilitate communication and collaboration to provide for requirements compliance and verification. 
TODOR TAGAREV is Head of the Defense and Force Management Department of "G.S. Rakovski" Defense and Staff College in Sofia Bulgaria and member of NATO's Research and Technology Board. He was the first Director of the Defense Planning Directorate since its establishment in early 1999. From May until late 2001, he served as Director for Armaments Policy in the Bulgarian Ministry of Defense and National Armaments Director. Among other duties, he coordinated all defense modernization and $R \& D$ programs in support of defense reform and NATO integration. He graduated from the Bulgarian Air Force Academy in 1982 and received a $\mathrm{PhD}$ degree in systems and control from Zhukovsky Air Force Engineering Academy, Moscow, in 1989. Dr. Tagarev is a 1994 Distinguished Graduate of the US Air Command and Staff College at Maxwell Air Force Base, Ala., and a 1994 Distinguished Young AFCEAn. E-mail: tagarev@gmail.com.

GUEORGUI STANKOV is a Chief Assistant Professor in the Defense and Force Management Department of "G.S. Rakovski" Defense and Staff College. He holds masters degrees in economics and business administration (Sofia University and Erasmus University, Rotterdam, 2004) and in computer science (Higher Military Artillery School, Shumen, 1989). Lieutenant Colonel Stankov is a graduate of the U.S. Command and General Staff College at Ft. Leavenworth, KS (2000) and has specialized in defense management in the United States and the United Kingdom. Before his present position LTC Stankov worked in the "Communications and Information Systems" Directorate of the General Staff and in a military research institute. Currently, he teaches acquisition management courses and conducts research in project and risk management. E-mail: gstankov@md.government.bg.

LOZAN BIZOV is Assistant Professor in the Air Force Department of the "G.S. Rakovski" Defense and Staff College in Sofia Bulgaria. He holds masters degrees in Electronics and Computation Systems from Bulgaria's Air Force Academy (1992) and in Operational Art and Science from the U.S. Air Command and Staff College, Maxwell AFB, Alabama (2003). Major Bizov has served at a variety of positions at Dobroslavtsi Air Base (1992-2000) and in the Interoperability Department of "G.S. Rakovski" Defense and Staff College (2000-2004), as well as in SFOR, Bosnia and Herzegovina (1997-1998). His professional interests include planning and execution of combined and joint air operations; air doctrine, and advanced air force-related technologies. E-mail: lozanmb@abv.bg.

ATANAS NATCHEV is Senior Researcher in the Defense Advanced Research Institute of the "G.S. Rakovski" Defense and Staff College in Sofia Bulgaria. He is a 1994 graduate of Bulgaria's Air Force Academy with a M.Sc. Degree in Mechanical Engineering, and since 1991 holds a Ph.D. degree from the "N.E. Zhukovsky" Air Force Engineering Academy in Moscow. Colonel Nachev has served as maintenance officer at an Air Base, in the Military Overhaul Plant in Plovdiv, and as Head of section "Armaments and Technology" in the Defense Planning Directorate of the Bulgarian Ministry of Defense. His main professional experience and interests are in aircraft structures and jet engines. E-mail: anatchev@md.government.bg. 